\title{
ESTUDO FLUIDODINÂMICO COMPUTACIONAL DE UM REATOR DE LEITO MÓVEL PARA TRATAMENTO DE EFLUENTE DA INDÚSTRIA DE CELULOSE E PAPEL
}

\author{
Y. N. KYRIAKIDIS ${ }^{1}$, L. G. M. VIEIRA ${ }^{1}$ e S. M. S. ROCHA ${ }^{2}$ \\ ${ }^{1}$ Universidade Federal de Uberlândia, Faculdade de Engenharia Química \\ ${ }^{2}$ Universidade Federal do Espírito Santo, Centro Universitário do Norte do Espírito Santo \\ E-mail: luizgustavo@feq.ufu.br
}

RESUMO - Os reatores de leito móvel são equipamentos largamente utilizados no tratamento secundário de efluentes. Apesar de serem compostos por apenas um tanque cilíndrico, o escoamento interno destes reatores é complexo, pois geralmente são escoamentos multifásicos, envolvendo o efluente líquido, sólidos inertes/biológicos e ar. A resolução das Equações de Transporte juntamente com condições de contorno adequadas podem ser uma alternativa viável para se obter maiores detalhes da fluidodinâmica interna do equipamento, tais como a previsão de zonas mortas, bypass, e linhas de corrente preferenciais. Desta forma, este trabalho teve como fundamento a aplicação de técnicas de CFD (Fluidodinâmica Computacional) para descrever, de forma preliminar, o comportamento fluidodinâmico bifásico no interior de um reator de leito móvel, focando-se na interação do binômio ar-água. Este estudo mostrou como a localização dos dutos de alimentação de ar, bem como a taxa mássica de alimentação do mesmo podem influenciar a hidrodinâmica do sistema. Para isso, as condições de contorno e as dimensões do reator para a confecção da malha computacional foram extraídas do trabalho experimental realizado por Nariyoshi (2011), que abordou o tema de tratamento secundário de efluentes na indústria de celulose e papel num reator de leito móvel. Os resultados observados após as simulações indicam um melhor contato entre as fases para maiores vazões de ar, combinada com a localização da entrada de gás no reator.

\section{INTRODUÇÃO}

A Indústria Química transforma matérias-primas em produtos finais, que abastecem o consumidor final, ou intermediários, que servem de insumos para outras indústrias. No decorrer da atividade industrial inevitavelmente são gerados resíduos que necessitam de tratamento específico a fim de se conter a contaminação do meio ambiente e de se respeitar a regulamentação imposta pelo governo. Conforme ilustra a Figura 1, geralmente um sistema de tratamento de efluentes pode ser descrito em três etapas: um tratamento preliminar para remoção de sólidos grosseiros; um tratamento primário para remoção de sólidos suspensos, ajuste de $\mathrm{pH}$, temperatura e dosagem de nutrientes; e, por fim, um tratamento secundário, utilizado com a finalidade de remoção de matéria orgânica, com a utilização de micro-organismos. Por envolver agentes biológicos, a etapa de tratamento secundário é considerada a mais delicada (Durán e Esposito, 1993). 


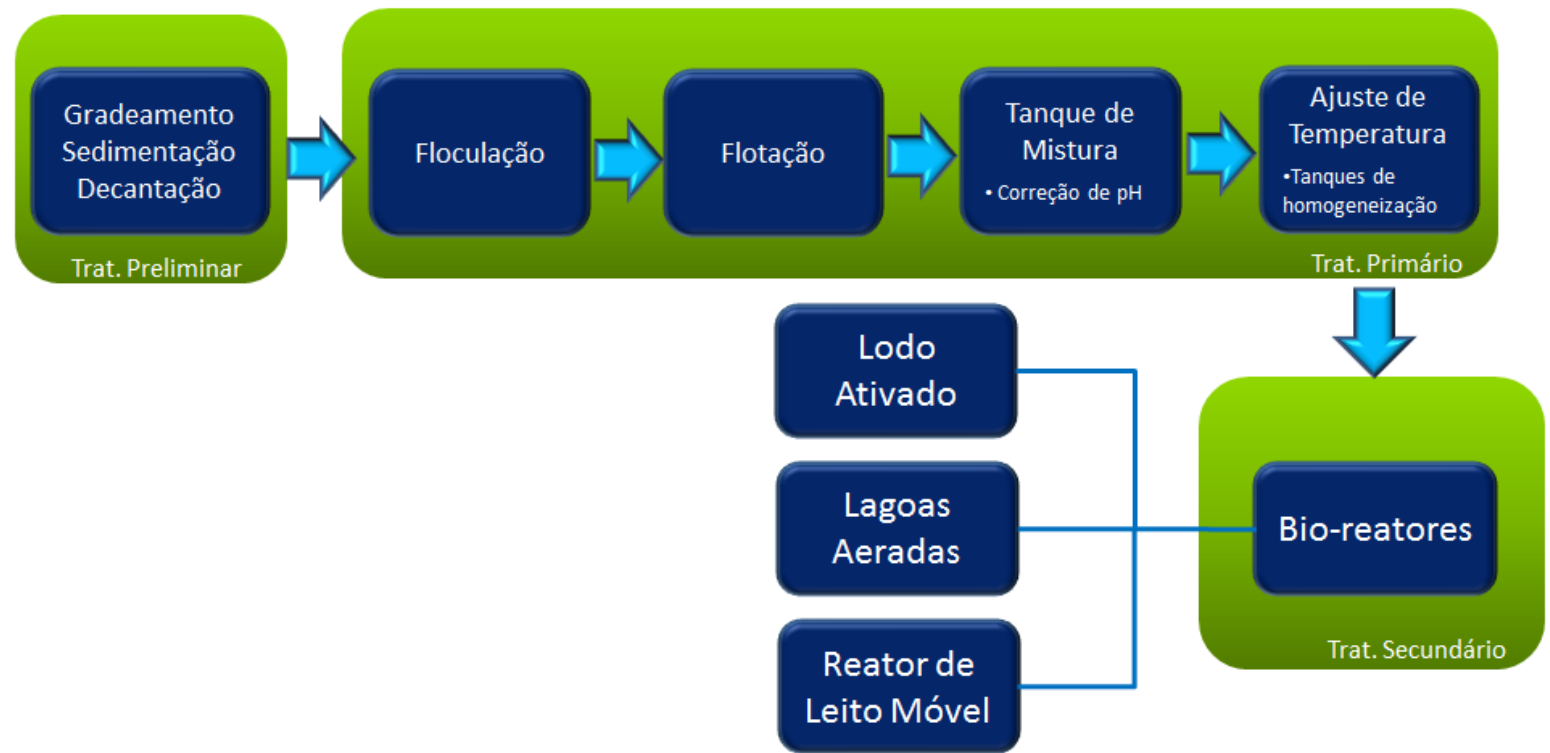

Figura 1 - Fluxograma simplificado do processo de tratamento de efluentes.

$\mathrm{Na}$ fase de tratamento secundário, algumas alternativas são viáveis: o uso do processo de Lodo Ativado, ou o uso de Lagoas Aeradas, ou, por fim, o emprego de Reatores de Leito Móvel, que é uma combinação dos dois processos anteriores, valendo-se da biomassa em suspensão e da biomassa aderida aos suportes. Habitualmente, o reator é descrito como aeróbio e opera num tanque cilíndrico com leito móvel (suportes) que promove a formação de biofilmes capazes de neutralizar a carga orgânica do efluente (Lazarova e Manem,1993).

Diversos estudos experimentais mostram a importância do uso de tecnologias mais modernas e eficazes no tratamento de rejeitos industriais. Porém, estes estudos se concentram principalmente no resultado final da reação microbiológica, bem como na otimização das condições globais do sistema sob a ótica da Engenharia Bioquímica. Ainda que apresentem resultados significantes, estes poderiam ser potencializados através do estudo fluidodinâmico do processo, através da aplicação de técnicas de CFD (Computational Fluid Dynamics ou Fluidodinâmica Computacional), pois já foi observado por Barreira (2003) que o comportamento do escoamento interno do reator influencia significativamente a reação, devido aos gradientes de concentração de reagentes e ao contato inter-fases.

A partir disso, o objetivo do presente trabalho foi analisar, por intermédio de simulações computacionais, o comportamento fluidodinâmico de um reator de leito móvel estudado por Nariyoshi (2011) em uma indústria de papel e celulose, dando ênfase ao escoamento bifásico ar e água, bem como realizar dois estudos de casos, observando como a localização dos dutos de alimentação de ar, bem como a taxa mássica de alimentação do mesmo podem influenciar a hidrodinâmica do sistema.

Dado que o setor de papel e celulose representa uma parcela dos grandes consumidores industriais de água, pois são necessários de 68,6 a 132,6 metros cúbicos de água por tonelada de produto final (Bachmann, 2009); ainda, o setor apresenta grande relevância econômica, visto que o Brasil ocupa a quarta posição na lista de produtores mundiais de celulose e a nona posição no ranking 
mundial de produção de papel, de acordo com Bracelpa (2012). Portanto, é de suma importância reduzir a quantidade de rejeitos industriais do setor, melhorando a performance do processo de tratamento dado aos efluentes desse ramo industrial.

\section{METODOLOGIA}

O reator estudado por Nariyoshi (2011) possuía um volume útil de $20 \mathrm{~m}^{3} \mathrm{em}$ forma cilíndrica, com 2,65 m de diâmetro e 3,62 m de altura. O reator é provido de uma entrada de líquido (efluente a ser tratado), duas entradas de ar e apenas uma saída. O diâmetro dos dutos de entrada de líquido e de saída da mistura são iguais a $5,08 \cdot 10^{-2} \mathrm{~m}$. Já para os dutos de entrada de ar, o diâmetro é igual a $3,00.10^{-2} \mathrm{~m}$. Um esquema representativo do problema em questão encontra-se na Figura 2. A malha computacional desse reator foi desenvolvida em duas dimensões e em escala real no software comercial Gambit ${ }^{\circledR}$. Ela é composta por aproximadamente 470000 elementos retangulares que, juntos, constituem uma malha estruturada.

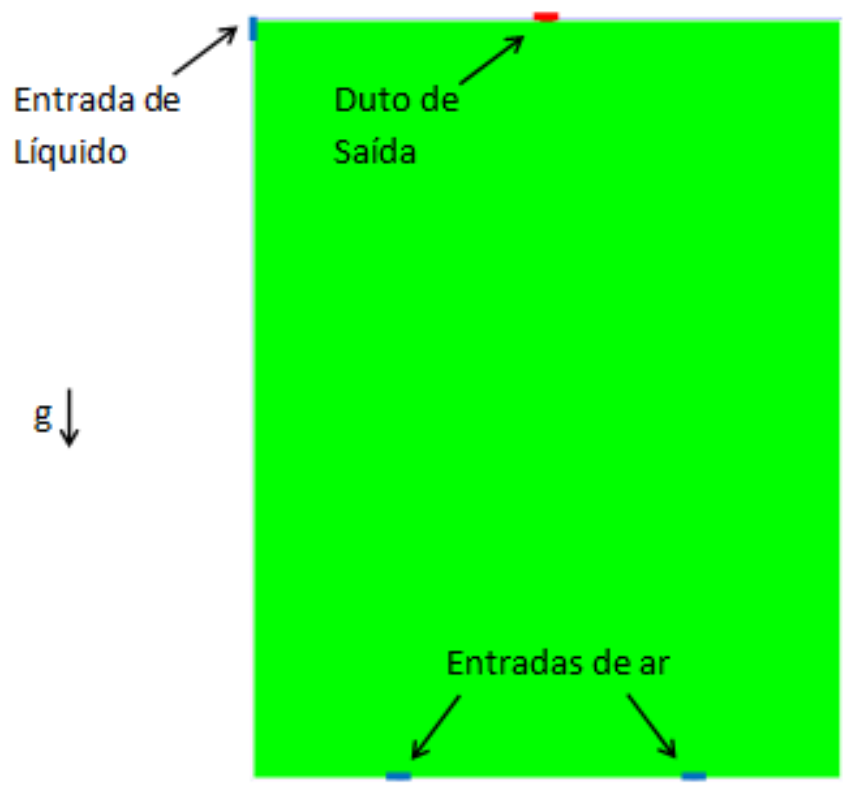

Figura 2 - Esquema representativo do reator descrito por Nariyoshi (2011).

Três simulações foram feitas por meio do resolvedor numérico Fluent $\AA$, comercializado e distribuído pela empresa Ansys®. A primeira das simulações teve como objetivo analisar o comportamento fluidodinâmico do reator estudado por Nariyoshi (2011). A segunda delas teve como intuito observar a influência da posição das entradas de ar, reposicionando-as na extremidade inferior da parede lateral do reator. Por fim, a terceira simulação focou-se em investigar a atuação da taxa mássica de alimentação de ar no escoamento interno do reator.

Como o objetivo foi um estudo preliminar sobre o assunto, foram conduzidas simulações bifásicas, observando-se apenas o binômio ar-água, em um sistema não reativo e onde inexiste a transferência de massa. Foi considerado escoamento transiente, isotérmico, incompressível e em condições ambientes de pressão e temperatura, sendo que a gravidade também foi contabilizada. A Tabela 1 traz, em detalhes, os modelos e parâmetros escolhidos para a simulação. 
Tabela 1 - Modelos e Parâmetros de Simulação

\begin{tabular}{|c|c|c|}
\hline \multicolumn{2}{|l|}{ Modelo Multifásico } & VOF \\
\hline \multicolumn{2}{|l|}{ Modelo de Turbulência } & RSM \\
\hline \multicolumn{2}{|c|}{ Algoritmo de Acoplamento Pressão-Velocidade } & SIMPLE \\
\hline \multicolumn{2}{|c|}{ Algoritmo para Cálculo de Pressão } & PRESTO! \\
\hline \multicolumn{2}{|c|}{ Função de Interpolação Espacial de Velocidade } & QUICK \\
\hline \multicolumn{2}{|c|}{ Tamanho de Passo no Tempo (segundos) } & $10^{-5}$ \\
\hline \multirow[t]{2}{*}{ Critérios de Convergência } & Fração volumétrica e Velocidades & $10^{-4}$ \\
\hline & Outras variáveis & $10^{-3}$ \\
\hline
\end{tabular}

Inicialmente o tanque encontrava-se completamente preenchido com água e observou-se a evolução da injeção de ar durante $30 \mathrm{~s}$ de tempo simulado, o que equivaleu a aproximadamente dois meses de esforço computacional. As condições de contorno utilizadas nas simulações encontram-se na Tabela 2.

Tabela 2 - Condições de Contorno das Simulações

\begin{tabular}{c|ccc}
\cline { 2 - 4 } \multicolumn{1}{c}{ Variável } & $\begin{array}{c}\text { Simulação do reator } \\
\text { de Nariyoshi }(2011)\end{array}$ & $\begin{array}{c}\text { Simulação da posição } \\
\text { alternativa de entradas } \\
\text { de ar }\end{array}$ & $\begin{array}{c}\text { Simulação da taxa } \\
\text { alternativa de entrada } \\
\text { de ar }\end{array}$ \\
\hline \hline $\begin{array}{c}\text { Vazão mássica de } \\
\text { entrada de afluente } \\
\text { líquido (água) }\end{array}$ & $1,6633 \mathrm{~kg} / \mathrm{s}$ & $1,6633 \mathrm{~kg} / \mathrm{s}$ & $1,6633 \mathrm{~kg} / \mathrm{s}$ \\
\hline $\begin{array}{c}\text { Vazão mássica de } \\
\text { entrada de ar total }\end{array}$ & $0,2042 \mathrm{~kg} / \mathrm{s}$ & $0,2042 \mathrm{~kg} / \mathrm{s}$ & $0,4084 \mathrm{~kg} / \mathrm{s}$ \\
\hline $\begin{array}{c}\text { Condição do duto de } \\
\text { saída }\end{array}$ & Pressão atmosférica & Pressão atmosférica & Pressão atmosférica
\end{tabular}

\section{RESULTADOS E DISCUSSÕES}

Através dos perfis simulados, foi possível obter maiores detalhes da fluidodinâmica interna do equipamento, tais como a previsão de zonas mortas, bypass, e linhas de corrente preferenciais. A Figura 3 mostra informações sobre a provável distribuição de fração volumétrica no reator estudado por Nariyoshi (2011) com o tempo. Apesar de não se ter alcançado o estado estacionário, constata-se que aos $30 \mathrm{~s}$ de escoamento há o predomínio da fase gasosa na parte superior do reator sendo que na parte inferior do mesmo forma-se um caminho preferencial de gás ascendente até, aproximadamente, a metade da altura do tanque. 


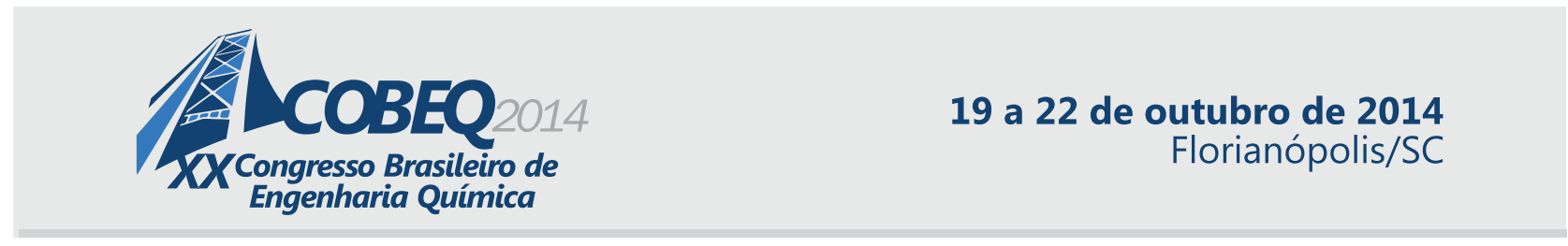

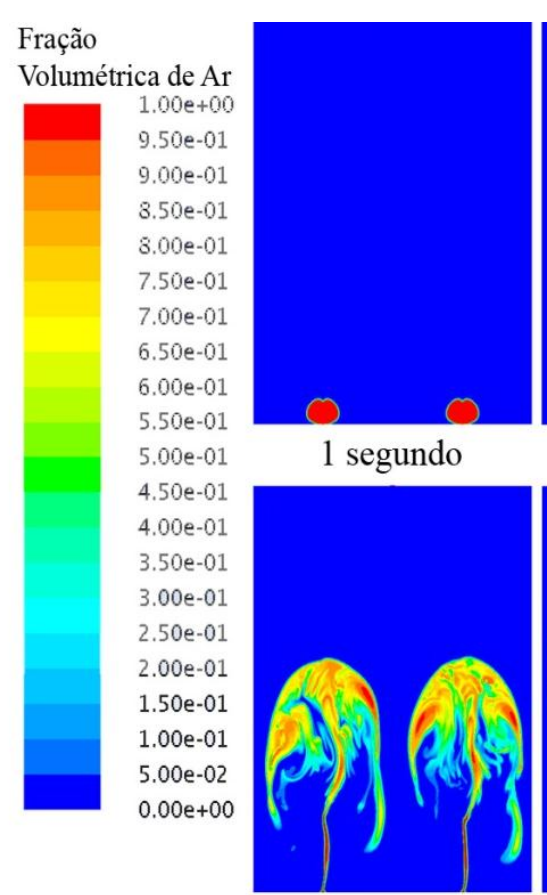

$10 \mathrm{~s}$

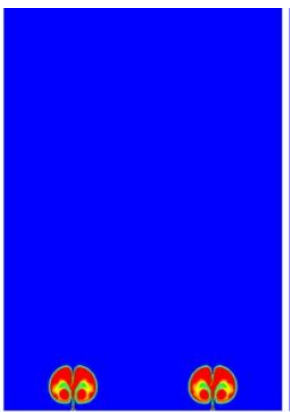

$2 \mathrm{~s}$

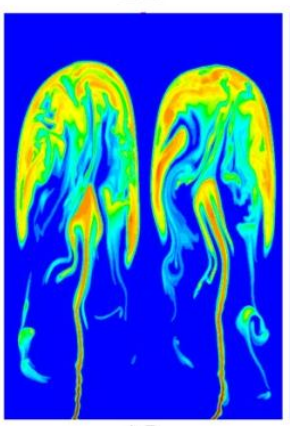

$15 \mathrm{~s}$

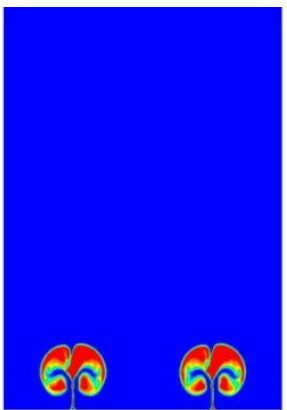

$3 \mathrm{~s}$

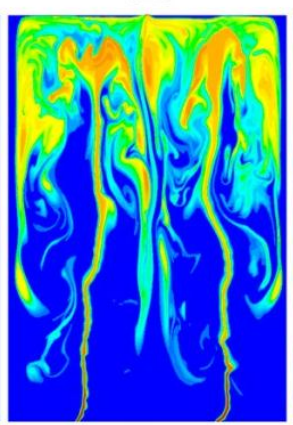

$20 \mathrm{~s}$

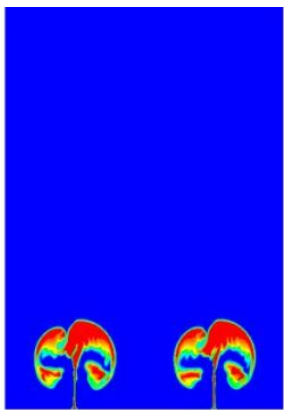

$4 \mathrm{~s}$

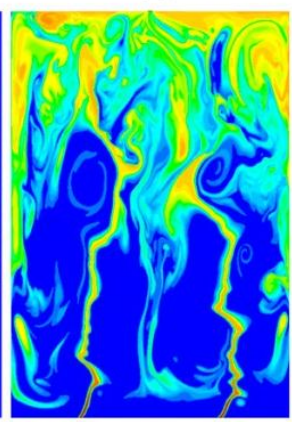

$25 \mathrm{~s}$

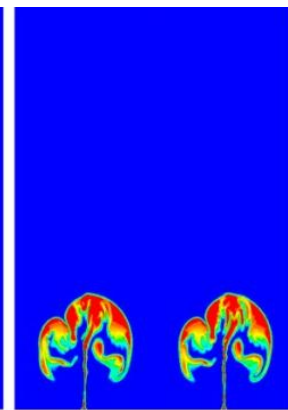

$5 \mathrm{~s}$

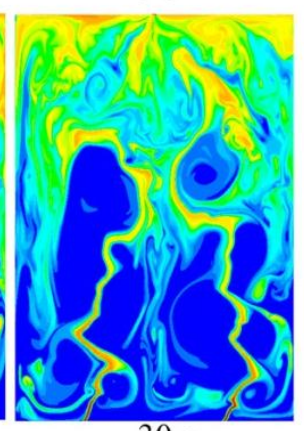

$30 \mathrm{~s}$

Figura 3 - Gráficos de distribuição volumétrica obtidos para a simulação do reator descrito por Nariyoshi (2011).

Por outro lado, a Figura 4 ilustra a tentativa de se aumentar o contato entre as fases, alterando-se a posição das entradas de ar. Nota-se que a nova proposta teve efeito completamente contrário ao esperado, já que a fase gasosa continuou seguindo um caminho preferencial, mas, desta vez, junto à parede do equipamento, formando grandes aglutinações de líquido na parte inferior central do tanque, até mesmo maiores do que o observado na simulação do reator nas condições de Nariyoshi (2011).

Tal resultado é devido à grande força hidrostática exercida pelo líquido inicialmente no tanque, o que implica em uma perda de carga maior a ser vencida, se o gás fosse capaz de adentrar mais internamente ao tanque. Ao atravessar o tanque preferencialmente pela superfície do líquido, o gás estará evitando forças adicionais que deveriam ser vencidas para chegar à saída do reator. Como a energia cinética aplicada ao ar provavelmente é insuficiente para que ele consiga transpor a barreira de água, a fase gasosa concentra-se nas regiões próximas à parede.

Pela Figura 5, pode-se visualizar que a simulação da taxa alternativa de ar leva a crer que existiria no sistema um maior contato efetivo entre as fases, especialmente na porção inferior do reator. Mesmo observando-se caminhos preferenciais de ar, onde a fração volumétrica desta fase é unitária, as regiões de predominância da fase líquida na base do tanque praticamente se extinguiram.

Provavelmente, a nova dinâmica de escoamento se deve à maior velocidade do ar, o que leva o mesmo a percorrer a distância até a altura máxima do tanque em um menor espaço de tempo, podendo contribuir para a estabilização mais rápida do sistema. Com isso, para um mesmo instante no tempo, a configuração de Nariyoshi (2011) resultaria em um nível de agitação e mistura menor do que aquela observada na simulação em que a vazão mássica de entrada de ar foi multiplicada por dois. 


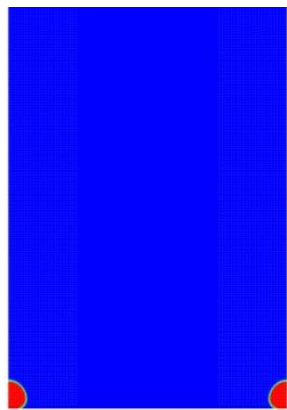

1 segundo

$5.00 \mathrm{e}-01$

$4.50 \mathrm{e}-01$

$4.00 \mathrm{e}-01$

$3.50 \mathrm{e}-01$

$3.00 \mathrm{e}-01$

$2.50 \mathrm{e}-01$

$2.00 \mathrm{e}-01$

$1.50 \mathrm{e}-01$

$1.00 \mathrm{e}-01$

$5.00 \mathrm{e}-02$

$0.00 \mathrm{e}+00$

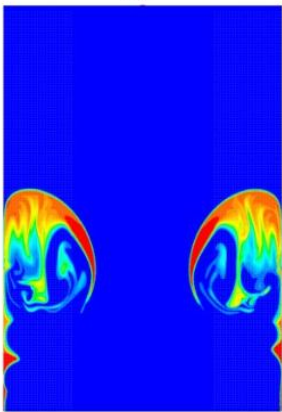

$10 \mathrm{~s}$

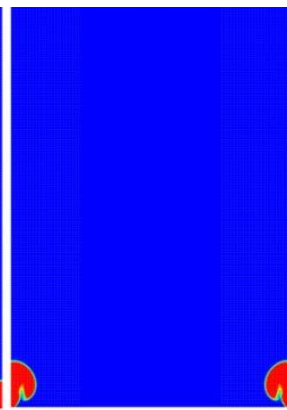

$2 \mathrm{~s}$

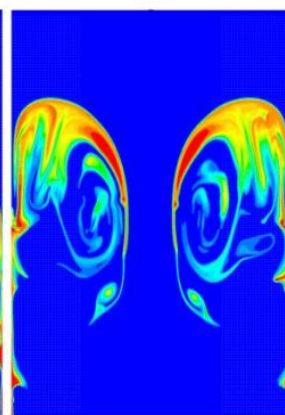

$15 \mathrm{~s}$

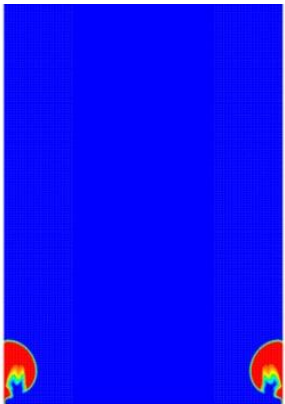

$3 s$

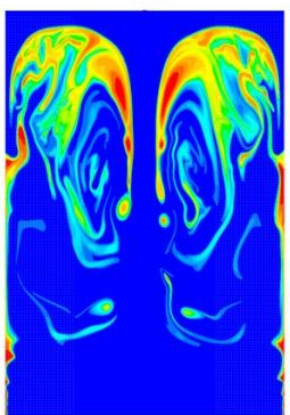

$20 \mathrm{~s}$

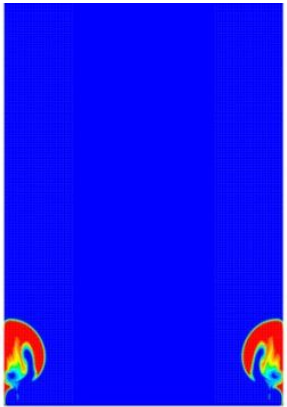

$4 \mathrm{~s}$

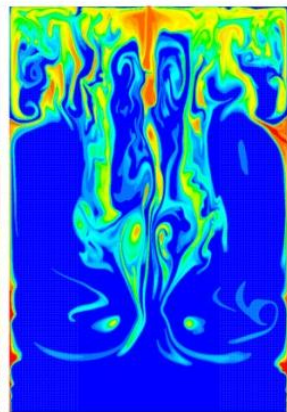

$25 \mathrm{~s}$

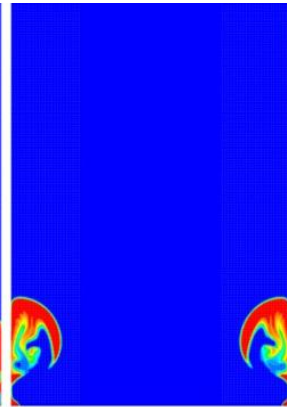

$5 s$

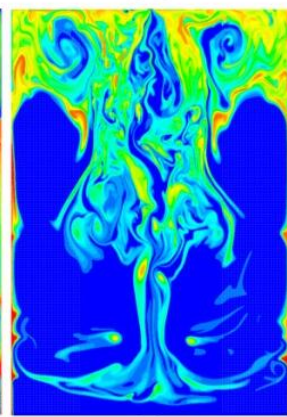

$30 \mathrm{~s}$

Figura 4 - Gráficos de distribuição volumétrica obtidos para a simulação da posição alternativa de entradas de ar.

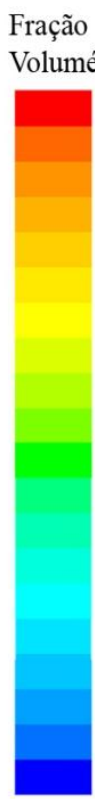

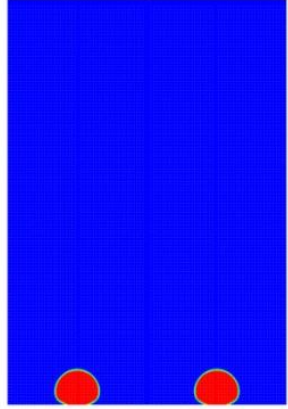

1 segundo

$5.00 \mathrm{e}-01$

$4.50 \mathrm{e}-01$

$4.00 \mathrm{e}-01$

$3.50 \mathrm{e}-01$

$3.00 \mathrm{e}-01$

$2.50 \mathrm{e}-01$

$2.00 \mathrm{e}-01$

$1.50 \mathrm{e}-01$

$1.00 \mathrm{e}-01$

$5.00 \mathrm{e}-02$

$0.00 \mathrm{e}+00$

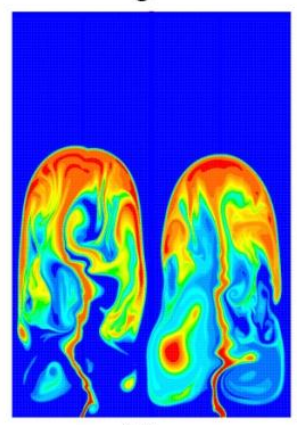

$10 \mathrm{~s}$

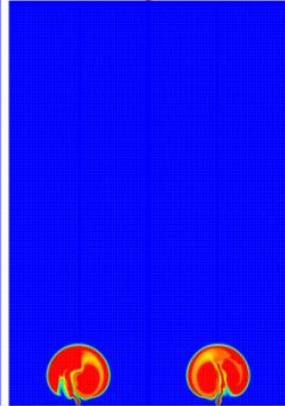

$2 \mathrm{~s}$

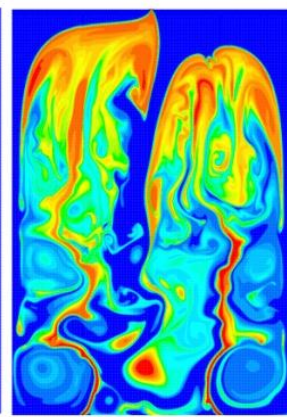

$15 \mathrm{~s}$

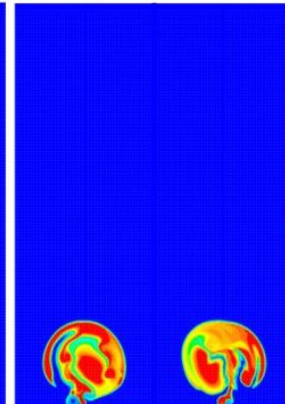

$3 \mathrm{~s}$

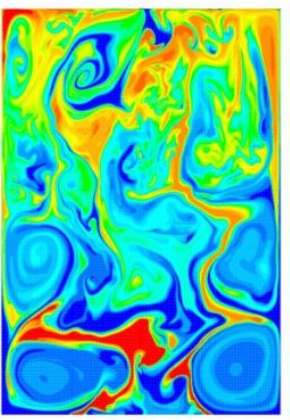

$20 \mathrm{~s}$

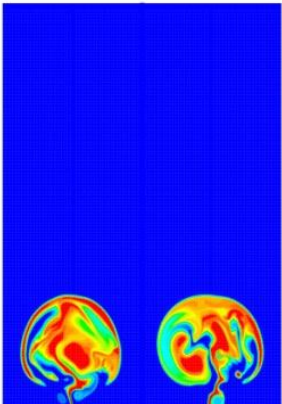

$4 \mathrm{~s}$

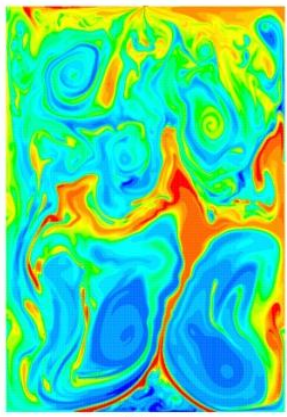

$25 \mathrm{~s}$

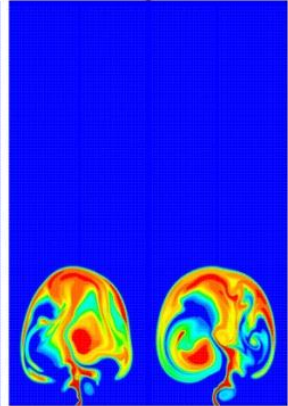

$5 \mathrm{~s}$

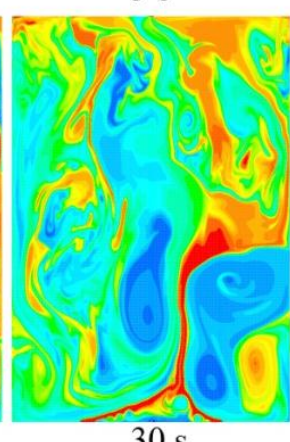

$30 \mathrm{~s}$

Figura 5 - Gráficos de distribuição volumétrica obtidos para a simulação da taxa alternativa de entrada de ar. 
Ainda, além dos gráficos de fração volumétrica, é possível analisar as figuras de linhas de corrente. Esse tipo de gráfico possibilita a análise tanto das linhas de corrente da fase líquida quanto da fase gasosa. A princípio, nenhuma das fases deve possuir regiões de bypass ou recirculação e ambas devem percorrer o maior caminho possível dentro do reator para aumentar o tempo de contato entre as fases. Dessa forma, foram analisadas as linhas de corrente ao final de cada simulação.

A Figura 6a mostra que o líquido alimentado não percorre todo reator, passando direto para a saída do mesmo. Esse bypass gerado prejudica a tratamento do despejo, pois sem contato adequado da a massa líquida com o restante do reator é impossível que o efluente seja devidamente tratado. Já a condição de posição alternativa de entradas de ar (Figura 6b), a alimentação de líquido adentra um pouco mais o interior do reator, mas, de fato, somente para maiores taxas de alimentação de ar, com entradas na posição original, é que o líquido conseguiria percolar todo o volume do reator (Figura 6c).

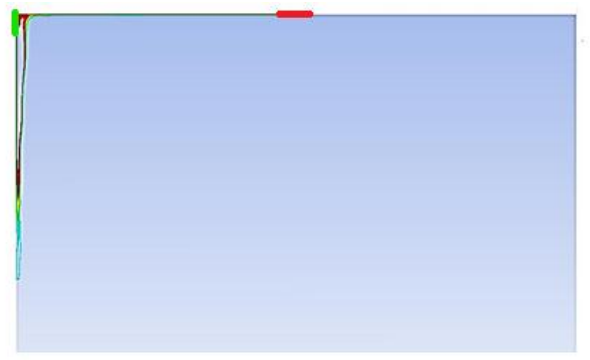

(a)

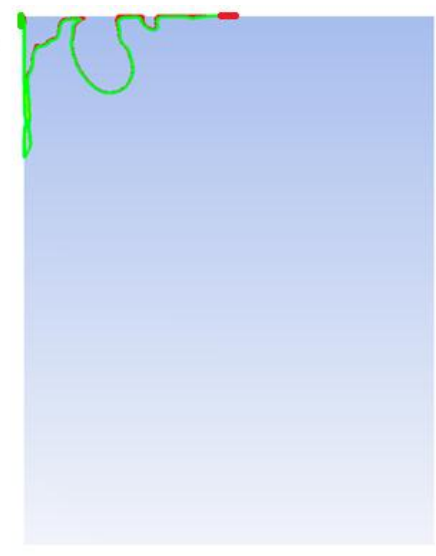

(b)

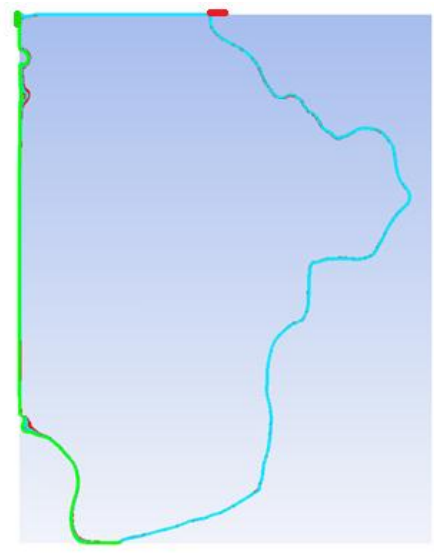

(c)

Figura 6 - Linhas de corrente de líquido ao fim de 30 s simulados: (a) ampliação da simulação da condição de Nariyoshi (2011), (b) simulação da posição alternativa de entradas de ar, (c) simulação da taxa alternativa de entrada de ar.

\section{CONCLUSÕES}

Dentre os casos simulados, a configuração de maior taxa de entrada de ar aparenta ser aquela onde há maior interação entre as fases líquida e gasosa ao final de $30 \mathrm{~s}$ simulados. Tendo em vista o aumento da performance do bio-reator, esta configuração indica oferecer a maior homogeneização do sistema com o maior contato entre as fases, possibilitando maior fornecimento de oxigênio ao sistema como um todo, além da maior taxa de renovação desse gás dentro do reator.

\section{AGRADECIMENTOS}

Os autores deste trabalho agradecem à FAPEMIG (PCE-00082/14) e ao Laboratório de Separação e Energias Renováveis (LASER) da FEQUI/UFU. 


\section{REFERÊNCIAS}

BACHMANN, D. L. O Papel. Benchmarking Ambiental na Indústria de Celulose e Papel. São Paulo, p. 57-61, junho, 2009.

BARREIRA, M. N. Introdução à modelagem em 3d para reatores air-lift empregando o "método dos volumes finitos" na resolução da fluidodinâmica (CFD). 264 f. Dissertação de Mestrado em Engenharia Química - PPGEQ, Universidade Estadual de Campinas, Campinas, 2003.

BRACELPA - ASSOCIAÇÃO BRASILEIRA DE CELULOSE E PAPEL. Dados estatísticos: Panorama do setor, 2012. Disponível em: <http:/www.bracelpa.org.br/bra2/sites/default/files/ estatisticas/booklet.pdf>. Acesso em: 08 de abril de 2014.

DURÁN, N.; ESPOSITO, E. New techniques in the reduction of the environment impact in the pulp and paper industry. Quim. e Indústr.. v.2, p.17-31, 1993.

LAZAROVA, V.; MANEM, J. Advance in biofilm aerobic reactors ensuring effective biofilme activity control. In: Internat. Conf. Spec. on Biofilm Reactors, Anais v.2, p.411-420, Paris, 1993.

NARIYOSHI, Y. N. Tratamento secundário do efluente final da indústria de celulose e papel com reator de leito móvel com biofilme (MBBR). 80 f. Trabalho de Conclusão de Curso de Engenharia Química - CEUNES, Universidade Federal Do Espírito Santo, São Mateus, 2011. 